\title{
MOLECULAR ASSISTED BREEDING FOR DISEASE RESISTANCE IN LILY
}

\author{
A.W. van Heusden, M.C. Jongerius, J.M. van Tuyl, Th.P. Straathof and J.J. Mes \\ Plant Research International BV \\ Department of Genetics and Breeding \\ PO Box 16 \\ NL-6700AA Wageningen \\ The Netherlands \\ a.w.vanheusden@plant.wag-ur.nl
}

Keywords: Lilium, AFLP markers, linkage map, Fusarium oxysporum, tulip breaking virus (TBV), quantitative trait loci (QTL)

\begin{abstract}
$\underline{\text { Abstract }}$
The Asiatic hybrid lily (Lilium L.) 'Connecticut King' harbours several beneficial traits such as partial resistance to Fusarium and complete resistance to tulip breaking virus (TBV). The variation in resistance to Fusarium was determined in four different greenhouse tests in four different years on the same 100 descendants of a backcross population. There was considerable variation in Fusarium resistance levels over the years. TBV resistance was determined and segregated, as expected, like a monogenic trait (1:1). In order to identify quantitative trait loci (QTLs) for Fusarium resistance and also to identify linked markers to the TBV resistance a QTL mapping approach was carried out in this backcross population. Segregation of 399 polymorphic AFLP ${ }^{\mathrm{TM}}$ (amplified fragment length polymorphism) fragments was determined. Two different enzyme combinations were used, Pst I/MseI and EcoRI/MseI, in the latter one extra selective nucleotide was added to the $M s e$ I primer. A paternal ('Connecticut King') linkage map was calculated. This map consisted of 24 linkage groups (Lilium $2 \mathrm{n}=2 \mathrm{x}=24$ ) with 251 markers covering $1367 \mathrm{cM}$. About $25 \%$ of the markers remained unlinked. Four QTLs for Fusarium resistance mapped to linkage groups 1, 5, 13 and 16 respectively. The resistance gene for TBV was placed on linkage group 9.
\end{abstract}

\section{Introduction}

The lily (Lilium L.) is one of the economically most important flower crops. One of the most serious threats in the lily cultivation is basal rot caused by the soil-borne pathogen Fusarium oxysporum f.sp. lilii. Breeding for resistance of lily is limited by the relative long juvenile phase, the relative slow propagation of clones and the lack of reliable screening assays during this phase. Screening tests at clonal level have been developed for Fusarium in lily (Straathof and Löffler, 1994a), however, these tests can only be performed several years after crossing and need retesting. Straathof and Löffler (1994b) showed that several genes are involved in the resistance mechanism.

Molecular markers linked to resistance traits, especially polygenic complex traits which are difficult to determine, can speed up breeding and selection processes drastically. Even with the introduction of many novel marker systems during the last 10 years reports of genetic mapping in ornamentals have been very few. For lily, one of the reasons for this is the large genome size compared to other plants like tomato (32-40 $\mathrm{x}$ $10^{6} \mathrm{~kb}$ vs. $0.7 \times 10^{6} \mathrm{~kb}$ ). Molecular markers have been used in lily for tracing parentages (Kazuhisa et al., 1998), identifying diversity (Wen and Hsiao, 2001) and for finding linked RAPD-markers to Fusarium oxysporum resistance in Asiatic hybrids (Straathof et al., 1996; Jansen, 1996). The huge size of the genome causes many problems in the use of RAPDs; such as rather poor reproducibility and high backgrounds. This paper describes the follow-up of the studies by Straathof et al. (1996) with exactly the same offspring 
population of a 100 plants but with another marker technology (AFLP) and with two extra disease screenings.

In this study we chose to use the AFLP marker system (Vos et al., 1995). For several species, with known large genomes, genetic maps based on AFLP have been published (Han et al., 1999, Van Heusden et al., 2000). These reports show that the AFLP is a suitable molecular marker that can be used for constructing genetic maps in species with huge genomes. In follow-up studies AFLPs can also be used for saturating selected genomic regions with many markers (Rouppe van de Voort et al., 1997, Cnops et al., 1996).

In this report we report on the construction of a genetic map of 251 AFLP markers based on 100 descendants of a lily backcross population. AFLPs and a QTL-approach were used to assess the level of polymorphisms between the different lilies and to pinpoint five chromosomal map regions, namely the region which harbours the resistance gene for TBV and four regions with an association with Fusarium resistance.

\section{Material and methods}

\subsection{Plant material}

The Asiatic hybrid lilies 'Connecticut King' and 'Pirate' were crossed. One $F_{1}$ hybrid, the cultivar 'Orlito', was used as father in a backcross with 'Connecticut King'. 'Connecticut King' is partially resistant to Fusarium and fully resistant to TBV, 'Pirate' is highly susceptible for Fusarium and TBV and 'Orlito' is partially resistant to Fusarium and susceptible to TBV. For further details about building up the mapping population see Straathof et al., 1996. A total of 100 descendants of this backcross population was used for the mapping studies.

\subsection{Fusarium and TBV test}

The Fusarium test was done according to Straathof et al.(1993). Observations were made six weeks after bulblets were planted. Severity of the disease infection was rated visually according to an ordinal scale with six categories: $1=$ healthy; $2=$ slightly rotten; $3=$ moderately rotten; $4=$ heavily rotten; $5=$ very heavily rotten; and $6=$ completely decayed. The presence of TBV was visually scored in several years, additionally a Elisa test was done to check for presence of the virus.

\subsection{AFLP $^{\mathrm{TM}}$ analysis}

DNA-isolation procedure and AFLP conditions have been described by Vos et al, (1995) and van Heusden et al. (2000). AFLP reactions were carried out with two different restriction enzyme combinations: Pst $/$ MseI (P31M47, P31M48, P31M49, P31M50, P31M51, P31M52, P31M54, P31M55, P31M59) and EcoRI/MseI (E37M52A, E37M52G, E37M52T, E40M52A, E40M52T, E41M52A). The primersequences have been described in detail by van Heusden et al. (2000) A total of six selective nucleotides was used for the two final primers in the combination Pst I/MseI $(+3,+3)$ and seven selective nucleotides in case of EcoRI/MseI $(+3,+4)$. Amplified fragments were separated on denaturating polyacrylamide gels. The AFLP fragments (size: 100 - $500 \mathrm{bp}$ ) were scored as dominant, i.e. presence vs absence of bands. All markers were scored twice and discrepancies were researched. AFLP markers were named with the names of the two primers (e.g. P35M52) followed by a number reflecting the fragment position on the gel. The numbers give the markers in descending molecular weight order.

\subsection{JoinMap}

Data were analysed using JoinMap 3.0 (Van Ooijen, J.W. and R.E. Voorrips, 
2001). A maternal map (i.e. 'Connecticut King') was calculated with segregating markers originally only present in 'Connecticut King' (segregation type abxaa) combined with segregating markers present in both parents (segregation type abxab). The determination of linkage groups of the markers was done with a LOD threshold of 4.0 with an occasional subdivision of a linkage group by raising the LOD threshold to 5.0. The calculations of the linkage maps were done using all pairwise recombination estimates smaller than 0.45 and a LOD score larger than 0.001. The Kosambi mapping function was used to convert recombination data to map distances.

\subsection{MapQTL}

Data were analysed using MapQTL ${ }^{\circledR}$ Version 4.0 (van Ooijen et al., 2000). For data analysis the nonparametric rank sum test of Kruskal-Wallis was used (see e.g. Lehmann 1975). This test measures the association between marker genotype and disease index and is therefore not affected by distorted segregation ratios.

\section{Results}

\subsection{AFLP analysis}

15 AFLP primer combinations with a number of fragments between 80-120 were used to generate 527 segregating AFLP markers together with many faint bands which were not scored. The average number of segregating fragments in the backcross population was 42 markers for EcoRI/MseI and 30 markers for Pst I/MseI type of markers. Both combinations were used to avoid the risk of clustering of AFLP-markers (Haanstra et al., 1999). Of the 527 segregating markers in the 'Connecticut King' x 'Orlito' cross 176 were originating from 'Connecticut King' and 201 from 'Orlito'; the remaining 150 markers were present in both parents and segregated in the offspring population.

\subsection{Linkage analysis}

251 of 326 segregating 'Connecticut King' markers were placed into linkage groups with a minimum of five markers, the determination of these linkage groups was done with a LOD threshold of 4.0 with an occasional subdivision of a linkage group by raising the LOD threshold. In total 24 linkage groups were identified (Table 1) covering approximately $1400 \mathrm{cM}$. Lily has twelve chromosomes and, therefore in an ideal scenario, only 12 different linkage groups should be found. markers.

Approximately $25 \%$ of the makers (75) were unlinked to groups of more than four

TBV resistance segregated in a perfect 1:1 ratio and was considered as monogenic trait (segregation type $a b \times$ aa). This gene was placed on linkage group 9. The linkages of TBV with the other markers are highly significant (ranging from LOD 6 to LOD 12). The closest marker to TBV is $9 \mathrm{cM}$. The closest linked markers are markers originally present in both parents (segregation type abxab). With the bulked segregant method (Michelmore et al., 1991) attempts were done to find more closely linked markers in coupling with the resistance gene. Over 80 different AFLP-primer combinations were tried but no markers were found.

\subsection{Fusarium resistance}

In four different years the segregation in Fusarium resistance was scored. The average scores differed between the years $(2.9+/-0.95,2.2+/-0.95,2.4+/-1.00$ and $2+/$ 0.5 for 1992, 1993, 1994 and 1999 resp.). Also the range of the resistance scores varied between the years (resp. 1.4-6, 1.0-5.4, 1.0-5.6, 1.1-3.7).

In order to link Fusarium resistance o the AFLP-map, the four data sets were 
analyzed separately. The Kruskal-Wallis statistic test gives the significance and the magnitude of the effects. The four different datasets were initially screened for effects with a significance higher than 0.995. Subsequently, the effects in all years for a particular chromosomal region were analyzed (Table 2). Four QTLs on four different linkage groups were detected but not all QTLs were detected every year, in most cases there was a less significant effect but even sometimes there was no significant effect at all in another year. All markers are in coupling phase with the resistance genes, plants having the marker show less susceptibility to Fusarium. Both 'Connecticut King' and 'Orlito' are partially resistant for Fusarium. The markers linked to the QTLs on linkage groups 1 and 5 were 'Connecticut King' markers not present in 'Orlito', therefore the QTLs were most probable also not present in 'Orlito'. The other two QTLs and their linked markers were present in both parents. No effects were detected originating from the susceptible grandparent 'Pirate'.

In the population of 100 plants 8 plants didn't have a single marker linked to one of the four QTLs. The average disease score of these eight plants was substantially higher than in the 15 plants with all four markers present (Table 3).

\section{Discussion}

For a straight forward identification of molecular markers linked to genes with an influence on traits of interest three prerequisites have to be fulfilled: a good marker system, a reliable assessment of the trait of interest and a population in which the trait clearly segregates.

In this study we used AFLP as molecular marker technique, the advantage of this technique is that it generates a lot of polymorphisms in a relatively short time. This is especially true in the highly heterozygous lily. Because the huge genome size of lily we had to adapt the original AFLP protocol by adding an extra selective base pair. Although many polymorphisms could be scored the overall picture was still complex and because of this we didn't attempt to score the segregating fragments present in both parents codominantly. Scoring these markers dominantly gives not enough linkage information to integrate parental and maternal linkage maps. The high level of unlinked markers can also be a consequence of the dominant scoring of these markers. Other reasons for a marker to remain unlinked are difficult scoring and duplicated loci (van Heusden et al., 2000)

Non-genetic differences over the years and differences in age of the plant material make Fusarium resistance a very difficult trait to handle with often low correlation between the years (Straathof et al., 1996). The fact that both parents of the cross were partially Fusarium resistant complicates the interpretation of the segregation data.

TBV resistance was clearly a monogenic trait and could reliably be mapped on linkage group 9. The closest linked marker, however, was still at a distance of about 10 $\mathrm{cM}$. The BSA-approach to find markers linked more closely (in coupling) failed, probably because by chance the susceptible 'Orlito' had only a very small introgression region with the susceptible allele of the resistance gene. In these cases only markers in repulsion can be expected. Another possible explanation is that there is a higher level of recombination in the vicinity of the TBV-resistance gene making the target region relatively small and consequently the chance to find markers low.

Despite the difficult screening for Fusarium resistance, four significant QTLs were detected, with the restriction that in some years some of the QTLs were not or hardly significant. This shows the necessity of doing several disease ratings. The plants with all QTLs present give an average value of 1.5 in 1999; in other words, these plants are scored as in between healthy and slightly rotten. For a more detailed study of the four QTLs and their individual contributions to the resistance, it will be necessary to convert the linked AFLP-markers to more robust PCR markers, markers which can also be scored co-dominantly.

This study shows that even under circumstances far from optimal (screening difficult, marker and mapping population also not perfect) it is still possible to identify the 
major QTLs for Fusarium resistance. The potential of marker assisted breeding for Fusarium resistance in practical breeding being more reliable than conventional selection, is enormous, as soon as linked markers can easily be assessed and selection can take place in an earlier stage of the breeding process.

\section{Acknowledgements}

This project was supported by the Dutch Government and the Dutch Commodity Board for Horticultural Products (PT). We thank our colleague from Plant Research International Dr. F.A. Krens for critically reading this manuscript.

\section{References}

Cnops G., De Boer B., Gerats A, Van Montagu M., and Van Lijsebettens M., 1996. Chromosome landing at the Arabidopsis TORNADO1 locus using an AFLP-based strategy. Mol Gen Genet 253: 1-2

Haanstra J.P.W., Wye C., Verbakel H., Meijer-Dekens F., van den Berg P., Odinot, P., van Heusden A.W., Tanksley S., Lindhout, P., and Peleman J., 1999. An integrated high-density RFLP-AFLP map of tomato based on two Lycopersicon esculentum x $L$. pennellii $\mathrm{F} 2$ populations. Theor Appl Genet 99 (1/2) 254-271.

Han T.H., van Eck H.J., de Jeu M.J., and Jacobsen E., 1999. Optimization of AFLP fingerprinting of organisms with a large-sized genome: a study on Alstroemeria spp. Theor Appl Genet. 98: 465-471.

Jansen R.C., 1996. A general Monte Carlo method for mapping multiple quantitative trait loci. Genetics 142 (1) :305-311.

Takashi H., and Youji N., 1998. Tracing the parentages of some Oriental hybrid lily cultivars by PCR-RFLP analysis. Journal of the Japanese Society for Horticultural Science 67 (3) 352-359.

Lehmann E.L., 1975. Nonparametrics. McGraw-Hill, New York, 457 pp

Michelmore R.W., Paran I., and Kesseli, R.V., 1991. Identification of markers linked to disease-resistance genes by bulked segregant analysis: a rapid method to detect markers in specific genomic regions by using segregating populations. Proc Natl Acad Sci USA. Washington, D.C. : The Academy. Nov 1, 1991. v. 88 (21) p. 9828-9832.

Rouppe van de Voort J., Wolters P., Folkertsma R., Hutten R., van Zandvoort P., Vinke H., Kanyuka K., Bendahmane A., Jacobsen E., Janssen R., and Bakker J., 1997. Mapping of the cyst nematode resistance locus Gpa2 in potato using a strategy based on comigrating AFLP markers. Theor Appl Genet 95 (5): 874-880

Straathof T.P., Jansen J., and Löffler H.J.M., 1993. Determination of resistance to Fusarium oxysporum in Lilium. Phytopathology 83 (5): 568-572.

Straathof Th.P., and Löffler H.J.M., 1994a. Resistance to Fusarium oxysporum at different developmental stages of Asiatic hybrid lilies. Journal of the American Society for Horticultural Science 119 (5) 1068-1072

Straathof, Th.P., and Löffler H.J.M., 1994b. Screening for Fusarium resistance in seedling populations of Asiatic hybrid lily. Euphytica 78 (1-2) 43-51.

Straathof Th.P., van Tuyl J.M., Dekker B., van Winden M.J.M., and Sandbrink J.M., 1996. Genetic analysis of inheritance of partial resistance to Fusarium oxysporum in Asiatic hybrids of lily using RAPD markers. Acta hortic. 414 p. 209-218.

Van Heusden A.W., van Ooijen J.W., Vrielink R., Verbeek W.H.J., Wietsma W.A. and Kik. C., 2000. Genetic mapping in an interspecific cross in Allium with amplified fragment length polymorphism (AFLP ${ }^{\mathrm{TM}}$ ) markers. Theor Appl Genet 100: 118-126

Van Ooijen J.W., and Voorrips R.E., 2001. JoinMapTM version 3.0: Powerful genetic linkage mapping made easy. Plant Research International, Wageningen, The Netherlands.

Van Ooijen, J.W., Boer M.P., Jansen R.C., and Maliepaard C., 2000. MapQTL (r) Version 4.0, Software for the calculation of QTL positions on genetic maps. Plant 
Research International, Wageningen, The Netherlands

Vos P., Hogers R., Bleeker M., Reijans M., van de Lee T., Hornes M., Frijters A., Pot J., Peleman J., Kuiper M., and Zabeau M., 1995. AFLP: a new technique for DNA fingerprinting. Nucl Acids Res 23: 4407-4414

Wen C.S., and Hsiao J.Y., 2001. Altitudinal genetic differentiation and diversity of Taiwan lily (Lilium longiflorum var. formosanum; Liliaceae) using rapd markers and morphological characters. Int J Plant sci 162 (2) :287-295.

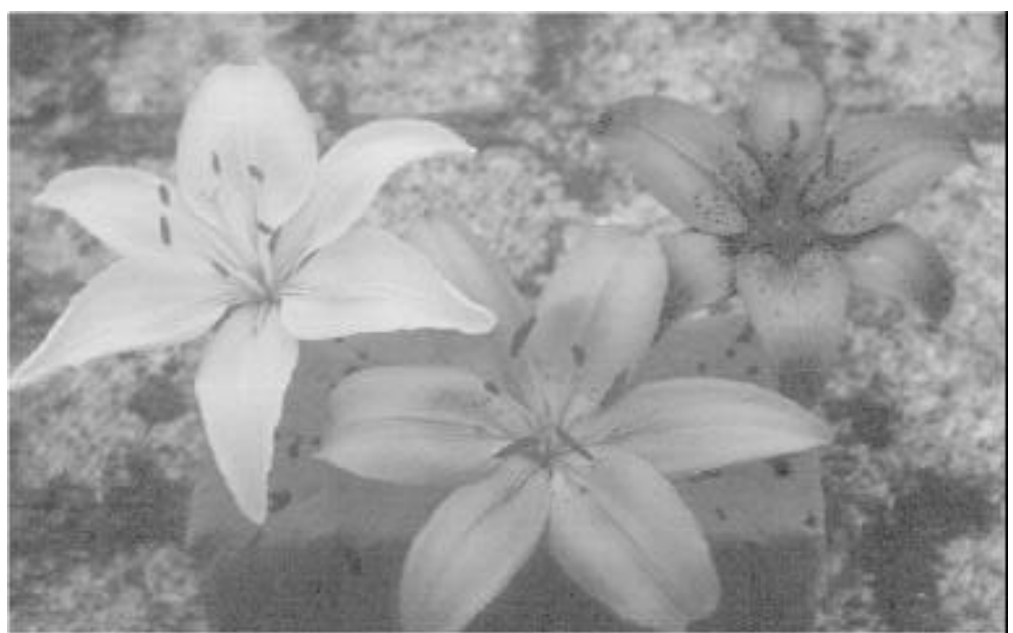

Figure 1. Asiatic hybrids 'Connecticut King' (left), 'Pirate' (right) and 'Orlito' (middle).
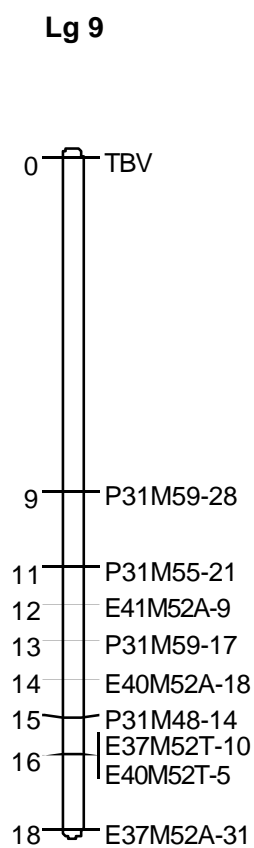

Figure 2. The lily linkage group harbouring the TBV-resistance gene. 
Table 1. The number of AFLP $(\mathrm{N})$, markers in each linkage group $(\mathrm{Lg})$ of lily and the map distance in $\mathrm{cM}$

\begin{tabular}{lll}
\hline $\mathrm{Lg}$ & $\mathrm{N}$ & $\mathrm{cM}$ \\
\hline 1 & 25 & 110 \\
2 & 20 & 60 \\
3 & 20 & 121 \\
4 & 15 & 60 \\
5 & 15 & 102 \\
6 & 15 & 62 \\
7 & 13 & 60 \\
8 & 13 & 90 \\
9 & $9+1$ & $10+9$ \\
10 & 12 & 163 \\
11 & 9 & 35 \\
12 & 9 & 37 \\
13 & 9 & 49 \\
14 & 8 & 26 \\
15 & 7 & 91 \\
16 & 7 & 20 \\
17 & 7 & 88 \\
18 & 6 & 20 \\
19 & 6 & 52 \\
20 & 6 & 6 \\
21 & 5 & 35 \\
22 & 5 & 20 \\
23 & 5 & 32 \\
24 & 5 & 18 \\
Sum & 251 & 1367 \\
\hline & &
\end{tabular}

Table 2. List of chromosomal regions with a significant linkage to Fusarium resistance in 1992, 1993, 1994 or 1999

\begin{tabular}{|c|c|c|c|c|c|}
\hline $\begin{array}{l}\text { Linkage group(and } \\
\text { position on map) }\end{array}$ & 1992 & 1993 & 1994 & 1999 & $\begin{array}{l}\text { Marker in region with highest } \\
\text { linkage }\end{array}$ \\
\hline $\begin{array}{l}\text { Linkage group } 1 \\
(17-27 \mathrm{cM})\end{array}$ & $* * * *$ & $*$ & - & $* * * *$ & E41M52A-35, E40M52A-27 \\
\hline $\begin{array}{l}\text { Linkage group } 5 \\
(65-90 \mathrm{cM})\end{array}$ & $* * * * * *$ & $* * * *$ & $* *$ & $* * * * *$ & P31M52-12, P31M59-21 \\
\hline $\begin{array}{l}\text { Linkage group } 13 \\
(35-50 \mathrm{cM})\end{array}$ & $* * *$ & $* *$ & $* *$ & $* * * *$ & E41M52A-1 \\
\hline $\begin{array}{l}\text { Linkage group } 16 \\
(0-20 \mathrm{cM})\end{array}$ & $* * *$ & $* * * *$ & $*$ & $* *$ & E41M52A-11, P31M55-1 \\
\hline
\end{tabular}


Table 3. Average of the disease ratings in the different classes

\begin{tabular}{lllll}
\hline & 1992 & 1993 & 1994 & 1999 \\
\hline Average (100 plants) & 2.9 & 2.2 & 2.4 & 2.0 \\
Without markers of all 4 QTLs (8 plants) & 3.6 & 3.5 & 3.1 & 2.3 \\
With markers of all 4 QTLs (15 plants) & 2.2 & 1.8 & 1.9 & 1.5 \\
\hline
\end{tabular}

